CUAD. CONTAB. / BOGOTÁ, COLOMBIA, 15 (38): 397-425 / JULIO-DICIEMBRE 2014 / 397

\title{
Evolución del proceso de armonización contable en España y Brasil en el período 1973-2013*
}

doi: 10.11144/Javeriana.cc15-38.epac

\section{Fernando Gracia-Sarubbi}

Profesor Universidad Europea de Madrid. Licenciado en Administración y Dirección de Empresas, Universidad de Buenos Aires, UBA, Argentina. Máster oficial en asesoría financiera y fiscal en el marco de las NIFF, Universidad Rey Juan Carlos, Madrid.

Correo electrónico: luisfernando.gracia@uem.es

\section{César Antonio San Juan-Pajares}

Licenciado en Ciencias Empresariales, Universidad Complutense de Madrid. Doctor en Economía Financiera, Universidad Complutense de Madrid. Profesor doctor, Universidad Europea de Madrid.

Correo electrónico: c_antonio.juan@uem.es

\begin{abstract}
Ángel Rodríguez-López
Licenciado en Ciencias Políticas y Sociología, Universidad Nacional de Educación a Distancia, UNED. Doctor en Ciencias Económicas y Empresariales, Universidad Complutense de Madrid. Profesor doctorado, Universidad Europea de Madrid. Profesor, Universidad Complutense de Madrid.
\end{abstract}

Correo electrónico: anrod20012000@yahoo.es; arlopez@ccee.ucm.es

\footnotetext{
* El proyecto que da origen al artículo es la Tesis doctoral del profesor Luis Fernando García, perteneciente al departamento de dirección de empresas de la Universidad Europea de Madrid. El título previsto de la tesis es El proceso de armonización contable internacional. Su finalización prevista es diciembre de 2015. El objetivo: investigar el grado de armonización contable de diferentes países al amparo de la nueva normativa IFRS. No es un trabajo financiado externamente.
} 
Resumen En este trabajo se analiza el proceso de normalización y armonización contable de las legislaciones financieras de España y Brasil. Ambos países han desarrollado sus normativas contables desde contextos financieros y económicos diferentes, pero se han orientado hacia un objetivo común: la aproximación a la armonización contable internacional. Se trata del inicio de un estudio de mayor amplitud que pretende investigar el proceso de acercamiento de ambos cuerpos normativos, y valorar el grado de armonización contable entre dos países con importantes relaciones económicas. Partiendo de la definición y los objetivos de la contabilidad internacional y su proceso armonizador, se expone la evolución de la normalización contable en ambos países, al examinar la modificación de sus normativas y los organismos que las promovieron. Así mismo, se presenta una revisión de la literatura sobre ambos procesos de armonización contable. Ambos países participan en este proceso armonizador desde la década de los 70, como queda demostrado tras analizar la evolución de sus cuerpos normativos.

Palabras clave NIC; NIIF; armonización contable; contabilidad internacional; sistema contable español; normativa contable brasileña. España, Brasil.

\section{Clasificación JEL F36, M41}

\section{Evolution of the Accounting Harmonization Process in Spain and Brazil During the 1973-2013 Period}

\footnotetext{
Abstract This work analyzes the accounting normalization and harmonization process of the financial regulations of Spain and Brazil. Both countries have developed their accounting regulations from different financial and economic contexts, but have aimed them towards a common objective: an approach towards international accounting harmonization. This is the beginning of a large-scope study that aims to research the convergence process of both bodies of regulations and assess the degree of accounting
}

harmonization between two countries with important economic relationships. The evolution of the normalization in accounting in both countries is presented, based on the definition and the objectives of international accounting and its harmonization process, by examining the changes to their regulations and the entities that encouraged them. Likewise, this work presents a review of the literature on both accounting harmonization processes. Both countries have taken part in this harmonization processes since the 70 's, as proven by the analysis of their bodies of regulations.

Keywords NIC; IFRS; accounting harmonization; international accounting; Spanish accounting system; Brazilian accounting regulations; Spain; Brazil

\section{Evolução do processo de harmonização contábil na Espanha e no Brasil no período 1973-2013}

Resumo Neste trabalho analisa-se o processo de normalização e harmonização contábil das legislações financeiras da Espanha e o Brasil. Ambos os países desenvolveram suas normativas contábeis desde contextos financeiros e económicos diferentes, mas tem se orientado para um objetivo comum: a aproximação à harmonização contábil internacional. Trata do início de um estudo de maior amplitude que visa pesquisar o processo de aproximação de ambos os corpos normativos, e valorar o grado de harmonização contábil entre dois países com importantes relações económicas. Partindo da definição e objetivos da contabilidade internacional e seu processo harmonizador, expõe a evolução da normalização contábil em ambos os países, ao examinar as mudanças das normativas e os organismos que as promoveram. Mesmo assim, apresenta-se revisão da literatura sobre ambos os processos de harmonização contábil. Ambos os países participam neste processo harmonizador desde a década dos 70, como demostrado após analisar a evolução dos seus corpos normativos. 
Palavras-chave NIC; NIIF; harmonização contábil; contabilidade internacional; sistema contábil espanhol; normativa contábil brasileira. España, Brasil.

\section{Introducción}

La armonización contable internacional ${ }^{1}$ es un proceso necesario para que las empresas que operan en diferentes países den a conocer su información financiera de forma comparable, para evitar duplicidades en la presentación de estados contables y diferencias en sus magnitudes y criterios contables.

Las empresas multinacionales son las principales impulsoras de este proceso (Lorca-Fernández, 2001), siendo los países desarrollados los que cambian sus legislaciones para normalizar las leyes nacionales y adaptarlas a la tendencia armonizadora (Pulido-Álvarez, 2001).

España y Brasil son dos de los países que han protagonizado este proceso de normalización ${ }^{2}$ legislativa y aproximación a las recomendaciones internacionales sobre armonización contable. Cada uno de ellos tiene un entorno económico y social diferente, por lo que sus legislaciones financieras son marcadamente distintas, habiendo evolucionado a desigual velocidad. En ambos casos, tienden hacia una mayor armonización contable, pero se han sustentado, inicialmente, sobre la base de legislaciones internacionales diferentes: las del

1 La armonización contable internacional es un proceso de carácter internacional, auspiciado por organismos supranacionales, cuyo objetivo es conseguir que diferentes países utilicen normas y estados contables similares y comparables. 2 El proceso de normalización contable tiene carácter nacional, y su objeto es adaptar la normativa financiera local para cumplir los requisitos planteados por las recomendaciones internacionales de armonización contable. entorno americano, para el caso de Brasil, y las del entorno de la Unión Europea para el caso español. No obstante, Brasil está reorientando su legislación hacia las normas internacionales a partir de 2007.

El país sudamericano se ha convertido en una potencia económica internacional y España es uno de los países europeos con mayor presencia de empresas que apoyan y aprovechan su potencial de crecimiento. Estas empresas y las empresas brasileñas que exportan productos o servicios a clientes europeos, se beneficiarán del proceso de armonización contable entre las legislaciones de los dos países.

En este artículo se analizan los procesos de normalización contable de ambos países y en último término, se ofrece una revisión de la literatura especializada que ha tratado ambos procesos. Así, se pretende valorar el grado de armonización que actualmente presentan ambos países entre sí, como caso particular para medir el desarrollo conseguido por las disposiciones de armonización financiera internacional en su conjunto.

El período observado es el comprendido entre los años 2000 y 2011. El mismo ha sido elegido teniendo en cuenta que la tendencia armonizadora apreciada en la mayoría de los países, a partir de 2005, se fue incrementando, con motivo de la apertura que la Unión Europea UE- hizo de sus legislaciones locales hacia un cuerpo normativo único, con el IASB como su ente emisor. De este modo, esta evolución pudo valorarse desde un antes y un después de ese hecho que marcó un hito sobre el particular.

La metodología utilizada en esta investigación es la del estudio comparativo. De acuer- 
do con Jordi Caïs (1997), para llevar a cabo comparaciones significativas de casos como un todo, se hace necesario comenzar por el examen de cada caso de forma directa y compararlo con otros casos importantes. El diseño de una investigación comparativa es simple. Se estudian reglas que pertenecen a un mismo grupo pero difieren en algunos aspectos. Estas diferencias llegan a ser el centro de atención de la investigación. El fin es detectar las causas y el origen de esas diferencias.

A partir de esas diferencias, se intenta determinar el grado de alejamiento o no de la normativa contable española y brasileña. Esto puede servir para indagar hasta qué punto las empresas españolas que han realizado inversiones en Brasil pueden verse afectadas o no por la implementación de prácticas contables distintas. Estos países están económicamente unidos. España como un inversor cada vez más importante en ese país, y Brasil como uno de los más interesantes mercados emergentes, receptores de la inversión extranjera. Esta relación se manifiesta por el creciente número de empresas españolas y brasileñas que operan en ambos países. Para este tipo de empresas, en particular, resulta relevante que las normativas contables tiendan a una completa armonización.

\section{El proceso global de normalización y armonización contable}

El proceso de globalización de la economía mundial ha definido la evolución de empresas y estados en el ámbito financiero. La denominada contabilidad internacional es la respuesta a la internacionalización de sus actividades y a las diferencias de criterio que se han originado en este nuevo escenario económico. Así, la contabilidad internacional engloba un conjunto de recomendaciones de carácter supranacional tendientes a la armonización contable, con el propósito de facilitar la comparación de la información financiera.

En la década de los 60, la contabilidad internacional se desarrolló en el ámbito de las empresas multinacionales, que realizaban actividades en dos o más países, para diversificar sus operaciones y buscar beneficios que permitieran financiar su expansión. En las siguientes décadas, estas empresas generaron un importante crecimiento de los negocios internacionales, lo que provocó la necesidad de adaptación de la contabilidad, que debía responder a la internacionalización del mercado de capitales y al registro de las nuevas inversiones directas en el extranjero de empresas con operaciones simultáneas en varios países. Este tipo de empresas necesita obtener información financiera comparable, dado que en la mayoría de los casos los requerimientos de las autoridades financieras diferían considerablemente.

Para entender la contabilidad internacional, es necesario tener presente el concepto de sistema contable, entendido como el conjunto de prácticas contables de un país determinado. Se trata de conceptos, principios generales y prácticas contables específicas de un país. En un contexto internacional, su definición debe ser válida, por medio de una orientación comparativa, para poder delimitar las diferencias existentes en el ámbito contable internacional (Laínez-Gadea, 2001). La estructura del siste- 
ma contable debe comprender como mínimo los siguientes elementos:

- Las líneas normativas maestras que definen la regulación contable.

- La manera en que se ha desarrollado la normativa contable y los agentes involucrados.

- El papel de los profesionales de la contabilidad.

- La formación de estos profesionales.

- Las prácticas contables naturales, a partir del marco normativo vigente, la información que producen y la manera de transmitir esa información a sus usuarios.

- Las tareas de auditoría de esa información, como una parte más del sistema contable.

Considerando sus propias necesidades, cada país diseña sus sistemas contables para satisfacerlas. Así, es lógico que surjan diferencias entre los sistemas contables internacionales; estas diferencias se deben principalmente a aspectos legales, económicos, políticos, de propiedad o estructura empresarial, culturales, etc. Influyen así mismo factores como la inflación, la normativa contable existente, el nivel de dirección empresarial, el desarrollo económico o el estatus de la profesión.

En coincidencia con José Luis Cea-García (2001), dada una situación de economías desiguales, con nivel de desarrollo, capacidad humana y educativa diferente, y hasta un mercado de capitales con características peculiares, la contabilidad debe estar preparada para responder a esa situación, también de forma desigual. Por esto, aun cuando hubiese un marco normativo internacional, respaldado por un organismo público, resultaría productivo que cada zona, modelo contable o grupo tuviera la posibilidad de desarrollar esta normativa teniendo muy en cuenta sus condiciones económicas, sociales y políticas.

Si se tienen en cuenta los dos grandes modelos de sistema legal, sus características influyen sobremanera en la forma de establecer la normativa contable. Así, Frederick D. S. Choi y Gary K. Meek (2011) proponen una clasificación según el sistema legal vigente, para diferenciar entre el basado en el derecho consuetudinario y el basado en el derecho normativo.

En los países cuyo sistema legal está basado en el derecho consuetudinario, la búsqueda de respuestas para cada caso en particular está por encima del dictado de normas de carácter general. Estos países pertenecen generalmente al área de influencia anglosajona. La normativa contable, por lo general, no impone criterios específicos, a saber, no revela de forma precisa la manera de elaborar los estados financieros. Las normas básicas provienen de la profesión contable más que de la norma legal, esto es, la regulación privada. Es el caso de Estados Unidos y su Financial Accounting Standards Board -FASB - Gran Bretaña, Canadá, Australia o Nueva Zelanda.

Lo contrario sucede en los países cuyo sistema se basa en el derecho normativo, en los que se desarrolla un marco normativo con un gran nivel de detalle y prácticamente todo queda establecido. Se trata de una regulación pública, que elabora la normativa contable, incluyendo la forma de presentar la información financiera, y que queda concretada en leyes mercantiles y planes de contabilidad. Son normas contables 
emitidas por organismos públicos como el Instituto de Contabilidad y Auditoría de Cuentas, ICAC, en España o el Conseil National de la Comptabilité (CNC) en Francia.

Por su parte, la normalización contable es un proceso que busca métodos y prácticas contables uniformes para la elaboración de la información contable de las empresas, para facilitar su análisis y comparación nacional. Entre sus objetivos pueden destacarse los siguientes:

- Orientar a los suministradores de información contable sobre cómo deben elaborarla.

- Guiar al auditor en la verificación de la información contable.

- Suministrar al usuario los criterios sobre cómo se ha elaborado la información contable (Arcas, Moneva \& Torres, 2003).

Además de los profesionales de la contabilidad y la auditoría, los gobiernos y los organismos públicos que regulan la actividad económica también se ven implicados. Los primeros contribuyen emitiendo la normativa contable. Los segundos hacen obligatoria la aplicación de esa normativa. Otros usuarios, aunque no participen directamente en la elaboración de normas contables, opinan sobre ellas e influyen así en los organismos emisores; es el caso, por ejemplo, de las entidades financieras o las empresas multinacionales.

En el ámbito internacional, la armonización contable busca unos criterios uniformes que permitan la aproximación de las normas y sistemas contables de diversos países. Esto se debe principalmente a los siguientes factores:

a. Los mercados financieros necesitan información contable suficiente y de calidad, que es generalmente elaborada con normativas diferentes en cada país. Los inversores en bolsas extranjeras reclaman la existencia de información contable comparable con la de sus propios países.

b. El aumento del comercio internacional demanda información contable entre las empresas. Operaciones como la adquisición de empresas en otros países convierte en imprescindible el intercambio de información contable.

c. Las empresas multinacionales son las principales interesadas en la armonización, dada la necesidad de elaborar los estados financieros consolidados con criterios homogéneos. O también para efectuar comparaciones con otras entidades, por ejemplo a la hora de realizar un análisis estratégico de expansión internacional.

Debe destacarse el papel desempeñado por el International Accounting Standards Board (IASB) en el ámbito de la armonización contable internacional. El IASB es un organismo internacional formado por otros organismos profesionales emisores de normas, entre los que se encuentran los más representativos del mundo, incluida la Comisión de la Unión Europea. Cuenta entre sus objetivos con los siguientes:

- Implementar un conjunto de normas contables únicas e internacionales, que faciliten la comparación de la información contable.

- Colaborar con los organismos nacionales de los distintos países para obtener la cohesión mundial de las normas contables. 
En una primera etapa, este organismo emitía las Normas Internacionales de Contabilidad (NIC) recomendando u ofreciendo la utilización de diversas alternativas de tratamiento contable para determinadas operaciones. En una etapa posterior, el IASB redujo el número de alternativas para la contabilización de determinadas operaciones, en un intento de mejorar la comparación internacional de la información contable. No solamente se revisaron las NIC ya emitidas sino que se redactaron otras nuevas. Las normas emitidas a partir de 2001 han pasado a llamarse Normas Internacionales de Información Financiera (NIIF), pero no se modificó el nombre NIC para las emitidas anteriormente.

No obstante, algunos autores - como Kene Cristina Pereira (2003) — sostienen que la adopción de las NIC/NIIF conlleva ventajas y desventajas. En cuanto a las ventajas, desde la perspectiva de la empresa, se encuentra la reducción de costes, el mayor control de las operaciones exteriores, el aumento de las facilidades de acceso a los mercados de capitales mundiales, y la simplicidad a la hora de consolidar y elaborar los estados financieros. Para Christopher Nobes y Robert Parker (1998), las desventajas engloban los costes de la formación y entrenamiento necesarios para permitir la estandarización de las normas.

En último término, la influencia del IASB ha sido creciente. Los países en desarrollo o recientemente industrializados vieron la oportunidad de contar con un conjunto de reglas contables que eran internacionalmente aceptadas y que ofrecían a la vez tranquilidad a los inversores extranjeros. Los países comunistas en transición hacia una economía de mercado, adoptaron las normas internacionales o apoyaron fuertemente sus propias reglas en ellas. China es un ejemplo relevante, porque ha elaborado su propia normativa sobre la base de la normativa internacional emitida por el IASB. En este sentido, pueden consultarse los trabajos de José Luis López-Combarros (2002a, 2002b) o Begoña Giner-Inchausti (2003), en los que se describe brevemente el mecanismo de emisión de una norma del IASB.

A continuación, se analizan los organismos y las regulaciones más relevantes relacionadas con la normalización contable de España y Brasil. Para ello, la metodología utilizada fue la del estudio comparativo, cuyo diseño de investigación es muy simple. Se estudian reglas que pertenecen a un mismo grupo pero difieren en algunos aspectos. Estas diferencias llegan a ser el centro de atención de la investigación. El fin es detectar las causas y el origen de esas diferencias. Comparar países distintos supone que se fija la atención en situaciones que ofrecen contrastes máximos y, además, significativos. Hay dos modos de comparar países:

- Contrastar países diferentes para reconocer características comunes que permitan ilustrar un proceso o fenómeno singular. De este modo, se puede llegar a la causa que produce un resultado común a todos ellos.

- También se los puede comparar para definir opuestos.

El resultado final de una comparación será la obtención de una conclusión breve, una estructura intelectual confeccionada a partir de la comparación efectuada (Caïs, 1997). 
La investigación objeto de este artículo consiste en el estudio comparativo que se hará entre España y Brasil. Más concretamente, entre la evolución de los procesos de armonización contable de ambos países. A partir de la comparación de una serie de variables, se podría determinar si es posible definir el grado de armonización actual de ambos países.

\section{Los reguladores contables: España versus Brasil}

España cuenta con dos tipos de normas contables: las de origen público y las de origen profesional. Las primeras están compuestas por el Código de Comercio, las Leyes de Sociedades y el Plan General de Contabilidad, además de otras normas emitidas por la Comisión Nacional del Mercado de Valores (CNMV), el Banco de España y la Dirección General de Seguros y Fondos de Pensiones (DGSFP). Las normas contables de origen profesional son las emitidas por la Asociación Española de Contabilidad y Administración de Empresas (AECA), integrada por un grupo de directivos de empresas, profesores universitarios, auditores, consultores de empresas y funcionarios especializados. Así mismo, el Instituto de Contabilidad y Auditoría de Cuentas (ICAC) es un organismo autónomo administrativo dependiente del Ministerio de Economía y Hacienda y creado en 1988. Su papel fue muy relevante en la normalización contable española ya que se encargó de crear un nuevo marco contable - el Plan General de Cuentas-, con el que se impulsaron las normas para la formulación de las cuentas anuales consolidadas, además de diversas adaptaciones sectoriales.
Por otra parte, en el caso brasileño hay cuatro organismos representativos de la labor reguladora: dos de carácter público (el gobierno y la Comisión de Valores Mobiliarios (Comissão de Valores Mobiliários, CVM)) y dos de carácter privado (el Consejo Federal de Contabilidad (Conselho Federal de Contabilidade, CFC) y el Instituto Instituto de Auditores Independientes de Brasil (Instituto dos Auditores Independentes do Brasil, IBRACON)).

En primer lugar, la Comissão de Valores Mobiliários, CVM, fue creada por la Ley 6404 de 1976 para proteger al pequeño accionista. Con el objetivo de velar por el buen funcionamiento del mercado bursátil, establece estándares contables de aplicación obligatoria para las empresas que cotizan en los mercados de valores: el informe de gestión y los estados financieros, las normas contables y los informes de los auditores independientes. Con su poder de fiscalización, constata las irregularidades y puede aplicar multas, suspensiones y hasta la incapacidad del profesional para el ejercicio de su cargo.

En segundo lugar, el Conselho Federal de Contabilidade, $\mathrm{CFC}$, es un organismo privado que cuenta con el respaldo de la autoridad pública. Representado en cada estado por los Consejos Regionales de Contabilidad (CRC), elabora resoluciones sobre principios y normas contables y fiscaliza el ejercicio de la profesión contable, al analizar y sancionar las infracciones.

Por último, el IBRACON, creado en 1971, emite pronunciamientos contables de aplicación obligatoria para sus miembros, que sirven de base para la redacción de principios y 
criterios contables y de auditoría. Representa al país ante entidades internacionales como el International Accounting Standards Commitee (IASC), la International Federation of Accountants (IFAC) o la Asociación Interamericana de Contabilidad (AIC).

\section{El proceso de normalización contable en España}

Hasta 1973, España contaba con una normativa mercantil que de manera general legislaba sobre aspectos formales de la contabilidad empresarial, complementada con normativa fiscal. En ese año, apareció el Plan General de Contabilidad, conocido como PGC73, que presentó un conjunto de normas contables de naturaleza estatal, para buscar la uniformidad en la elaboración y presentación de la información contable. Además, el PGC73 se ajustaba a los principios de la contabilidad tradicional y reconocía así mismo la relevancia de los modelos contables orientados a la gestión. Más adelante, se creó el Plan General de Contabilidad Pública, de estructura similar al PGC73, y de aplicación a todas las entidades públicas, con excepción de las sociedades.

Posteriormente, mediante la Ley 19/1988 se creó el Instituto de Contabilidad y Auditoría de Cuentas (ICAC), organismo autónomo administrativo dependiente del Ministerio de Economía y Hacienda. Su papel fue muy relevante en la normalización contable española ya que se ha encargado de crear un nuevo marco contable nacional.

A partir de 1989, se procedió a la adaptación de la legislación mercantil española a las directivas de la UE, para regular aspectos re- lacionados con la información contable y las cuentas anuales, así como los criterios fundamentales para su elaboración, publicación y auditoría. La nueva legislación mercantil quedó compuesta por el Texto Refundido de la Ley de Sociedades Anónimas (Real Decreto Legislativo 1564/1989), el Plan General de Contabilidad (Real Decreto 1643/1990), las Normas para la Formulación de la Cuentas Anuales Consolidadas (Real Decreto 1815/1991), la Ley de Sociedades de Responsabilidad Limitada (Ley 2/1995) y el Reglamento del Registro Mercantil (Real Decreto 1784/1996). Las principales modificaciones trataban el objetivo de imagen fiel del patrimonio, de la situación financiera y de los resultados de la empresa. Así mismo, se procedió a separar la normativa fiscal de la contable, se reguló la publicidad y auditoría de las cuentas anuales y se aumentaron los requerimientos de información financiera a las empresas y a los grupos de empresas mediante la consolidación.

Por otra parte, como consecuencia del Reglamento 1606/2002/CE del Parlamento Europeo y del Consejo Europeo, se produce la aparición en el caso español de la Ley 16/2007, de reforma y adaptación de la legislación mercantil en materia contable para su armonización internacional con base en la normativa de la UE, de forma que tanto en el Código de Comercio como en la Ley de Sociedades Anónimas se han introducido las modificaciones que permitieron progresar en el proceso de convergencia ${ }^{3}$

\footnotetext{
3 Se utiliza en este artículo el término convergencia como la acción y efecto de concurrir a un mismo fin, utilizando la definición ofrecida por la Real Academia Española de la Lengua (RAE). En nuestro caso particular, el fin es la armonización de las legislaciones contables.
} 
internacional. Se persiguió la idea de garantizar que esta adaptación de la contabilidad española no interfiriera en el régimen jurídico de cuestiones fundamentales de las sociedades mercantiles como la distribución de beneficios, la reducción obligatoria de capital social y la disolución obligatoria por pérdidas. La Ley 16/2007 concedió al gobierno la competencia para aprobar el Plan General de Contabilidad, mediante Real Decreto, según lo dispuesto en las Directivas Comunitarias y teniendo en cuenta lo establecido en las NIC/NIIF adoptadas por los Reglamentos de la UE. Además, se faculta al gobierno para aprobar otro texto complementario más centrado en las necesidades de las pequeñas y medianas empresas. El ICAC procedió así a trabajar en un borrador del nuevo plan. Más concretamente, técnicos del propio instituto, profesionales, académicos, expertos contables, profesores universitarios y representantes de la Administración Pública fueron los responsables de su redacción. En especial, las diferencias entre la normativa contable vigente hasta el momento en España y las NIC/NIIF, sobre las que trabajaron fueron básicamente las siguientes:

- La normativa española utiliza en general el principio de precio de adquisición, que difiere del valor razonable que permiten las normas del IASB para determinados elementos patrimoniales.

- A las diferencias de cambio positivas en moneda distinta del euro, la normativa española aplica un régimen de diferimiento mientras que las NIC/NIIF las consideran un ingreso del ejercicio.
- Con las filiales cuyas actividades son muy distintas a las del resto del grupo, el IASB no respalda su exclusión a la hora de consolidar y aplica para ello el método de integración global. España aplica a estos casos el procedimiento de puesta en equivalencia.

- Algunos aspectos regulados por el IASB no lo están por la normativa española. Es el caso del estado de flujo de efectivo, informaciones a revelar sobre partes relacionadas referidas a ganancias por acción, información financiera por segmentos, fusiones y escisiones, etc.

Actualmente, la normativa contable española está basada en el concepto de imagen fiel y separa los ámbitos contable y fiscal. Así, la contabilidad española se regula siguiendo las siguientes normas, a saber, Código de Comercio de 1885 y sus respectivas modificaciones; Real Decreto 1514/2007, Plan General de Contabilidad; Real Decreto 1515/2007, Plan General de Contabilidad de Pequeñas y Medianas Empresas y, por último, Real Decreto 1/2010, texto refundido de la Ley de Sociedades de Capital.

De esta forma, en primer término, el Código de Comercio ha sido siempre la norma fundamental de naturaleza mercantil. Publicado por Real Decreto en 1885, ha sufrido sucesivas modificaciones motivadas en principio por la evolución de la economía española pero también por la adaptación obligatoria a la legislación de la UE. Señala los libros obligatorios para los empresarios, requisitos para su publicidad y el carácter secreto de la contabilidad. Hace obligatoria la formulación de las cuentas anuales y establece los principios y criterios 
aplicables en la valoración de las partidas que los componen.

En segundo lugar, el Real Decreto 1514/2007, Plan General de Contabilidad, mantiene la estructura del PGC90, dada su gran aceptación. En su primera parte, el Marco Conceptual de la Contabilidad, se reúnen los documentos que integran las cuentas anuales, así como los requisitos, principios y criterios contables de reconocimiento y valoración, que buscan que las cuentas anuales muestren la imagen fiel del patrimonio, de la situación financiera y de los resultados de la empresa, en consonancia con lo dispuesto por el Código de Comercio. La segunda parte, Normas de Registro y Valoración, agrupa los criterios de registro y valoración de las diferentes transacciones y elementos patrimoniales de la empresa en general. La tercera parte, Cuentas Anuales, recoge las normas para la formulación de las cuentas anuales, al tiempo que modelos, normales y abreviados, de los documentos que las integran. La cuarta parte, Cuadro de Cuentas, lista los grupos, subgrupos y cuentas necesarios, debidamente codificados en forma decimal, y con un título expresivo de su contenido. Pensando en que la normalización contable española alcance el grado de flexibilidad suficiente, no será obligatoria su aplicación. La quinta parte, Definiciones y relaciones contables, comprende las definiciones de las distintas partidas que se incluirán en el balance, en la cuenta de pérdidas y ganancias y en el estado de cambios en el patrimonio neto, así como las de cada una de las cuentas que se recogen en esas partidas, incluyendo los principales motivos de su cargo y abono.
Entre otras, en el Real Decreto 1514/2007 se introducen las siguientes novedades:

- El concepto de valor razonable para registrar además de ciertas correcciones valorativas, los ajustes de valor por encima del precio de adquisición en instrumentos financieros a los que se aplican las reglas de la contabilidad de coberturas.

- Para el inmovilizado material, se agrega al precio de adquisición, el valor actual de las obligaciones derivadas de su oportuno desmantelamiento. Los gastos financieros ocasionados por la adquisición o construcción de activos hasta la fecha de su puesta en marcha serán activados, a condición de que tales activos necesiten más de un año para estar en condiciones de ser utilizados.

- Hay inmovilizados intangibles con vida útil indefinida, los que no serán amortizados. No obstante, si su valor se ha deteriorado, se contabilizará la correspondiente pérdida.

- Con respecto a los gastos de primer establecimiento, serán gastos del ejercicio en el que tengan lugar. Los gastos de constitución y ampliación de capital se imputarán directamente al patrimonio neto, sin pasar por la cuenta de pérdidas y ganancias. Formarán parte de las variaciones de patrimonio neto que se reflejan en el estado de cambios en el patrimonio neto.

- Se incorpora la categoría de activos no corrientes disponibles para la venta, con la particularidad de que no serán amortizados. En el balance, formarán parte del activo corriente, ya que se prevé recuperar su valor en libros mediante su venta y no mediante su uso en la actividad ordinaria de la empresa. 
Así mismo, las cuentas anuales están integradas por el balance, la cuenta de pérdidas y ganancias, el estado de cambios en el patrimonio neto, el estado de flujos de efectivo y la memoria. Con el propósito de facilitar la comparabilidad en la información financiera, se han confeccionado unos modelos de formato definido y de obligatoria aplicación.

En tercer lugar, el Real Decreto 1515/2007 aprueba el Plan General de Contabilidad de Pequeñas y Medianas Empresas, que instaura un cuerpo normativo de aplicación para que las pyme cuenten con un plan contable completo y específico. Consta de una estructura similar al Plan General de Contabilidad, aunque con algunas diferencias, basándose en el tamaño de las empresas objeto de regulación. Su ámbito de aplicación es cualquier empresa, independientemente de su forma jurídica, que durante dos ejercicios consecutivos reúnan a la fecha de cierre de cada uno de ellos al menos dos de los siguientes requisitos:

- Que el total de las partidas del activo no supere los 2.850.000 euros.

- Que el importe neto de su cifra anual de negocios no supere los 5.700 .000 euros.

- Que el número medio de trabajadores empleados durante el ejercicio no sea superior a cincuenta.

Por último, con la intención de unificar la regulación de las sociedades anónimas, sociedades de responsabilidad limitada y sociedades comanditarias por acciones, entró en vigor la Ley de Sociedades de Capital (Real Decreto Legislativo 1/2010). Con su aparición, quedaron derogadas las siguientes normas: la Sección 4 del título I del libro II (artículos 151 a 157) del Código de Comercio de 1885, concerniente a la sociedad en comandita por acciones; el texto refundido de la Ley de Sociedades Anónimas (Real Decreto 1564/1989); la Ley 2/1995 de Sociedades de Responsabilidad Limitada; $y$, por último, el Título $\mathrm{X}$ de la Ley 24/1988 del Mercado de Valores, en lo referente a sociedades anónimas cotizadas.

Este Real Decreto contiene las disposiciones de la normativa que deroga; quedan excluidas las sociedades mercantiles personalistas. Además, introduce algunas modificaciones en las normas relativas a las sociedades anónimas y de responsabilidad limitada; algunas de carácter general, comunes a ambos tipos societarios, y otras específicas para cada una de ellas. Se estructura en catorce títulos, cada uno de los cuales está dividido en varios capítulos y secciones. Entre los temas relevantes en relación con el asunto que nos ocupa, podemos destacar la inclusión de pautas relativas a las aportaciones sociales, responsabilidades de los socios, participaciones sociales y acciones, la administración de la sociedad, las cuentas anuales, etc. Pero lo más novedoso en la legislación española es el establecimiento del concepto de sociedades de capital.

\section{El proceso de normalización contable en Brasil}

La contabilidad brasileña ha estado tradicionalmente influida por las normas estadounidenses, debido a su posición geográfica y a la gran presencia comercial de Estados Unidos en los países sudamericanos. Pese a esta influencia, en 1993 se creó el Grupo de Integración del Mercosur, Contadores, Economistas y Ad- 
ministradores (GIMCEA), con la intención de armonizar el ejercicio contable profesional de los países pertenecientes a ese mercado común. Este grupo de trabajo resultó ser un importante impulso regional al proceso de armonización contable internacional. Sobre la base de las NIC/NIIF, como un conjunto inspirador y significativo de normas contables para avanzar en los procesos de armonización, se recomendó el uso de criterios similares para la emisión de las normativas nacionales correspondientes.

Un paso destacable fue la resolución 10/2004 de la Cámara de Educación Superior (CES) y del Consejo Nacional de Educación (CNE) del Ministerio de Educación y Cultura de Brasil. Se destacó la necesidad de insertar la contabilidad internacional en el currículo de las carreras superiores relacionadas con las ciencias contables. La utilización de normas internacionales de contabilidad depende de la efectividad de profesionales calificados, los que deben estar capacitados para actuar en su país, pero también más allá de sus fronteras.

Así mismo, Brasil también sigue un sistema contable legal, emanado de la normativa contable en vigor. La misma está conformada principalmente por la Ley 6404/1976 y las importantes modificaciones que le fueron introducidas por las leyes 11638/2007 y 11941/2009, con la intención de aproximarla a las normas internacionales.

En efecto, a mediados de la década de los 70, se definieron por primera vez en Brasil los objetivos de la información contable, para determinar unos criterios valorativos y de información de modo informal, en los que prevalecieron claramente los criterios fiscales sobre los contables. En 1976, con la aprobación de la Ley de
Sociedades (Ley 6404/1976), comenzó la regulación de los aspectos mercantiles de las sociedades que realizan actividades comerciales en Brasil. Esto se debió al progresivo desarrollo del mercado bursátil y la aparición de mercados más transparentes. Esta ley establece cuestiones relativas a la elaboración de los estados contables. El principal usuario de la información contable de las empresas es el Estado, al que le siguen las entidades financieras, proveedores, accionistas, etc. La normativa contable se implementa mediante Leyes y Decretos Federales.

Dadas las nuevas necesidades del país, fue sancionada la Ley 11638/2007, que introdujo grandes cambios en la contabilidad empresarial, en especial en la Ley de sociedades por acciones (ley 6404/1976), que modificó las leyes vigentes hasta ese momento, que databan de 1976. El objetivo era homogeneizar la legislación vigente con las normas internacionales del IASB. Así, por ejemplo, se sustituyó el estado de orígenes y aplicaciones de recursos por el estado de flujo de caja. Incorpora también dos nuevos grupos de cuentas: en el activo permanente, la cuenta de bienes intangibles para contabilizar los bienes que sin existencia física representan una aplicación del capital indispensable para los objetivos de la empresa (derechos sobre marcas y patentes, fondo de comercio).

También por medio de esta ley, se hizo obligatoria la inclusión de expertos contables en todos los organismos públicos relacionados con la normalización contable. Siguiendo estas disposiciones legales, la contabilidad de las empresas se llevará a cabo considerando períodos de un año (ejercicio social). Al finalizar un ejercicio económico la empresa tiene que elaborar 
los estados financieros, con la intención de reflejar la situación patrimonial de la misma y los cambios ocurridos en ese período. Los estados financieros son los siguientes:

- Balance patrimonial

- Estado de pérdidas y ganancias acumuladas

- Estado de resultado del ejercicio

- Estado de flujos de caja

- Estado de valor añadido (obligatorio para sociedades de capital abierto)

El plan de cuentas utilizado en Brasil está conformado por un conjunto de cuentas creado por el responsable de la contabilidad de la empresa para atender a las necesidades de registro de las diferentes transacciones, de modo tal que facilite su consideración por parte de todos los usuarios de la información contable. Tiene la función principal de ofrecer una forma de control del patrimonio empresarial. Así, un plan de cuentas debe ser elaborado teniendo en cuenta las siguientes características (Padoveze, 2009):

- Debe dar prioridad a las necesidades específicas de cada empresa y a las necesidades de información de los principales usuarios.

- La clasificación debe ir de lo general a lo particular.

- Debe estar codificado.

- Los grupos de cuentas se pensarán en función de los informes a los que darán origen.

- Los títulos de las cuentas deben referir inmediatamente a los elementos patrimoniales que representan.

- Debe tener flexibilidad y operacionalidad.

Para su codificación se pueden establecer diferentes grados. Así, en primer grado estarán los números 1, 2, 3 y 4 para el activo, pasivo, gastos e ingresos, respectivamente. Aumentando el nivel de detalle, el plan de cuentas en segundo grado, de tercer grado y así sucesivamente.

Los Principios Fundamentales de Contabilidad conforman las reglas que dan estructura teórica a la contabilidad y al análisis contable en Brasil. Están contenidos en la Resolución 750/1993, del Conselho Federal de Contabilidade, CFC, bajo la denominación de Principios contables generalmente aceptados, de aplicación obligatoria. En particular, son entidad, continuidad, oportunidad, registro por su valor de origen, actualización monetaria, competencia y prudencia.

Adicionalmente, el CFC emitió la Resolución 1374/2011 en la que estableció una estructura conceptual para la elaboración y presentación de los estados financieros, aplicable a los ejercicios iniciados el 1 de enero de ese mismo año. Entiende que si los estados financieros son elaborados según estas normas, se satisfacen las necesidades comunes de la mayoría de los usuarios de la información financiera. Destaca la importancia cualitativa de tal información según las características fundamentales de relevancia e imagen fiel. También subraya otras características como comparabilidad, verificabilidad, temporalidad y comprensibilidad.

\section{Los procesos de convergencia contable en España y Brasil: revisión de la literatura}

Las legislaciones contables de España y Brasil han aproximado sus normas a los requerimientos de la armonización internacional. Ambos 
países han modificado sus normativas financieras para facilitar el proceso de convergencia. En este apartado se revisan los trabajos de diversos autores y organismos que han analizado estas modificaciones y sus consecuencias en cada uno de estos países en términos de armonización internacional.

Conviene destacar que hasta la fecha analizada no hay trabajos que comparen directamente los conjuntos normativos contables de España y Brasil. De hecho, las únicas investigaciones relacionadas son la de Ilse Maria Beuren, Rodrigo dos Santos-Cardoso, Carlos Eduardo Facin-Lavarda y Vicente M. RipollFeliu (2009), Gestão de matérias primas em indústrias de conserva de pescado do Brasil e da Espanha; y Luana Paula de Souza-Barros, Chein-Schekaiban, Nazhle F. Josir SimeoneGomes y Vicente Ripoll-Feliu (2008), Estudo comparativo na área de contabilidade gerencial entre Brasil, México e Espanha. Estos artículos no contienen una comparación directa de ambas legislaciones, sino otros aspectos relacionados con la contabilidad de gestión.

En ese trabajo se citan artículos que de forma directa o indirecta comparan la legislación contable de estos países con otras legislaciones. Tomando el año 2005 como eje, se ha elegido como período de investigación el comprendido entre los años 2000 y 2011, para observar el antes y el después de la evolución de las normativas contables en los países implicados. Tanto España como Brasil implementaron a partir de 2007 importantes reformas a su normativa local, con la intención de alcanzar un acercamiento a esa normativa internacional. Así, esta revisión comienza con la comparación de la legislación española con la UE y las NIC/NIIF. Posteriormente, se tratan los trabajos que comparan la legislación brasileña con la UE, NIC/ NIIF y la legislación estadounidense.

\section{A. Trabajos que tratan la legislación contable española y europea y sus grados de armonización}

En este ámbito se puede citar el trabajo de Begoña Giner-Inchausti (2003), que analiza las principales diferencias entre las normas internacionales y las españolas antes de la reforma del PGC. Así mismo, Manuel Rejón-López (2005) realizó una investigación para obtener una visión global de sus repercusiones en los principales entes involucrados en la implementación de las NIC/NIIF en España. Para ello, consideró el período enero de 2003 hasta febrero de 2005, ya que era el intervalo para llevar a cabo las pruebas necesarias para analizar, probar y plantear la estrategia contable y financiera respecto de las NIC/NIIF, partiendo de 110 artículos de prensa económica especializada española.

Por otra parte, con información financiera de los ejercicios contables 2005-2006, Erlend Kvaal y Christopher Nobes (2010) investigaron diversos países como Alemania, Australia, Francia, Reino Unido y España, para comprobar la existencia de diferencias respecto de la normativa internacional. Todos estos países tienen en común la obligatoriedad de aplicación de esa normativa, por lo menos en lo relativo a la consolidación, al tiempo que cuentan con mercados financieros importantes. Propusieron diversas hipótesis apoyadas en varias de las prácticas sugeridas por la normativa internacional para die- 
ciséis puntos de aplicación sobre las principales empresas cotizadas de esos países. Concluyeron que las diferencias persisten tanto en asuntos triviales como más complejos. Desde el criterio de liquidez para ordenar los activos del balance hasta la forma de realizar un cash-flow.

Otros estudios comparan la normativa contable entre España y otros países de la Unión Europea - como el de Beatriz CuéllarFernández, Paola Demartini, José Mariano Moneva-Abadía y Mauro Paolini (2001), que se fundamenta en el hecho de que a finales del año 2000, el 60\% del volumen de los negocios comunitarios era facturado por pyme- $y$ hacen un análisis sobre la utilidad de la información exigida a la pyme. Dirigieron cuestionarios a pyme italianas y españolas para comparar ambos entornos y medir la armonización real de la información financiera para este tipo de empresa. Al comparar ambos marcos contables, se observa la utilización de criterios distintos en cuanto a la publicación de la información financiera. Mientras las empresas españolas, cualquiera sea su tamaño, deben presentar cuentas anuales similares, en Italia las sociedades de responsabilidad no limitada solo deben cumplir los criterios de valoración aplicables a las de responsabilidad limitada, con un cierto margen de libertad en la presentación de la información. De este modo, quedaba claro que no hay armonización de la información financiera para la pyme en la UE en los casos analizados.

Otra investigación de interés fue la realizada por Xavier Sabi-Marcano, Ramón Saladrigues-Sole, Anna Vendrell-Vilanova y Anna Tena-Tarruella (2001) en la que se intentó comparar las cuentas anuales de empresas de diversos países de Europa, entre ellos España. Hasta esas fechas, la adaptación de las directivas comunitarias supuso un gran adelanto en la armonización contable europea, aunque sin superar las particularidades que cada sistema contable ha conservado. Los resultados obtenidos evidenciaron la falta de homogeneidad ante cualquier análisis comparativo de la información financiera de las empresas europeas, manifestada en los siguientes atributos, a saber: diferencias en las fuentes estadísticas; diferencias provenientes del propio entorno legal de cada país, tanto en lo fiscal como en lo contable; diferentes objetivos de utilización de la información que buscan los países; contenido heterogéneo de las cuentas anuales; diversidad idiomática; $y$, por último, diferentes formatos bajo los cuales se presenta la información.

Otro estudio relevante es el realizado por Antonio M. Olleros-Rodríguez (2008) en el que se elabora un cuadro comparativo que recoge el estado de implementación de las NIC/NIIF. Así, por ejemplo, frente a la posibilidad de las sociedades que cotizan en bolsa de elaborar sus estados financieros individuales según estas normas, el 53\% de los países, incluido España, no lo permite. Así mismo, debe considerarse el trabajo realizado por Arturo Giner-Fillol, Gregorio Labatut-Serer y Vicente Ripoll-Feliu (2009) sobre la adaptación de la normativa española a las normas internacionales de contabilidad.

En el ámbito contable europeo, las directivas europeas IV (78/660/CEE) y VII (83/349/CEE) iniciaron un proceso de armonización que con el tiempo se tornó insuficiente para atender las necesidades tanto de los usuarios como de las empresas, en especial las que buscan financia- 
ción en los mercados bursátiles. Así, Begoña Giner-Inchausti y Araceli Mora-Enguídanos (2001) recopilaron diversos trabajos de investigación sobre la armonización contable en Europa y se plantearon el reto de analizar la interdependencia entre los resultados de esos trabajos de investigación y la realidad económica. Para estas autoras, normalización implica uniformidad en la normativa propia de cada país involucrado, en tanto que armonización supone reconciliación internacional de los distintos puntos de vista. La normalización puede permitir precisiones distintas en los países involucrados (siempre que no supongan una disyuntiva). La mayor parte de la literatura en materia de contabilidad internacional hasta la promulgación de las directivas versaba sobre estudios descriptivos sobre la contabilidad de diversos países. De esta forma, su análisis sirvió para dejar constancia de que la diversidad era un hecho y contribuyó a identificar aspectos diferenciales destacables. El estudio más revelador fue el de Christopher Nobes (1984), ya que permitió organizar a los países europeos en dos grandes grupos: anglosajón y continental. Las variables que utilizó para tal clasificación fueron el sistema legal, el sistema financiero y el sistema fiscal de los países.

Así mismo, Begoña Giner-Inchausti (2008) investigó sobre el grado de aceptación de las NIC/NIIF que emitía el IASB por parte de los países europeos, luego del Reglamento 1606/2002/CE del Parlamento Europeo que les daba sanción. El hecho de que se aplicaran en un centenar de países permitió concluir que la aceptación por parte de los mercados financieros estaba siendo muy alta. También se tornaron obligatorias para países como Aus- tralia, Nueva Zelanda y Sudáfrica, o territorios como Hong Kong. Incluso más: Brasil, Canadá, China, India o Japón tomaron medidas para admitirlas en un futuro no muy lejano. Así mismo, la US Securities and Exchange Commission - SEC - descartó la obligación de presentar ajustes por parte de las empresas extranjeras que utilizan las NIC/NIIF.

Finalmente, Nobes (2008) investigó sobre las diferencias internacionales respecto de la forma en que los países fueron respondiendo a las NIC/ NIIF. Algunos países las adoptaron por completo, como Chipre. Algunos otros permiten su adopción para la consolidación de empresas que cotizan en bolsa y para las que no (Reino Unido). Algunos las aceptan para algunos fines pero para otros no (Francia). Y los hay también que no las han aceptado todavía (Estados Unidos, con la excepción de compañías extranjeras). En otros países, la normativa nacional subsiste, aunque la tendencia es a la convergencia con las NIC/ NIIF (China, para las empresas cotizables). De la misma investigación, surgen dos tipos de países dentro de la UE, a saber: los que destacan el patrimonio empresarial y dan más importancia a los aspectos comerciales, y los que no dan tanta importancia al patrimonio empresarial, pues destacan un papel más dominante por parte del Estado y los aspectos fiscales. En el primer grupo se encuentra Holanda, mientras que en el segundo está España.

\section{B. Trabajos que tratan la legislación contable brasileña y su grado de armonización}

En primer lugar, Jorge Katsumi-Niyama (2010) en Contabilidade Internacional resalta la impor- 
tancia de la contabilidad internacional para Brasil y resalta la necesidad de que los profesionales de la contabilidad conozcan las normas internacionales emanadas de los organismos que las regulan. Así, la principal contribución de esta obra consiste en analizar las diferencias de la contabilidad brasileña respecto de la internacional, al realizar un estudio comparativo entre las normas locales y las de otros países, a partir de diez transacciones que han generado muchas divergencias entre ellas: gastos de investigación y desarrollo; revalorización de activos; contabilización del leasing financiero; contabilización del goodwill (fondo de comercio); actualización de inventarios por el método UEPS (últimas entradas primeras salidas) o LIFO (last in first out); impuestos diferidos; planes de jubilación para empleados con cargo a beneficios; instrumentos financieros; conversión de transacciones y estados financieros en moneda extranjera; $y$, finalmente, contratos de construcción (emprendimientos a largo plazo). En este sentido, el autor citado dedica un capítulo al estudio comparativo de los países integrantes del modelo anglosajón y del de la Europa continental: Estados Unidos, Gran Bretaña, Alemania y Francia. Del mismo modo, se ocupa también del caso japonés por contar con características de uno y otro modelo.

Por otra parte, Alceu Haruo-Fuji (2008) demuestra la utilización de la normativa contable internacional (normas IASB) no solo en países desarrollados, sino también en mercados emergentes, como el caso de algunos países de Latinoamérica. Son de aplicación en más de cien países, los que representan la mayor parte del mercado mundial de capitales. Canadá, Japón,
Nueva Zelanda y Hong Kong ya se valen de ellas; y varios países latinoamericanos también.

Así mismo, Inés García-Fonti (2008) analiza la implementación de esta norma internacional en Latinoamérica, con los siguientes resultados. Brasil no permite de momento el uso de las NIC/NIIF, aunque desde 2010 son obligatorias para las empresas cotizadas. Lo mismo para Chile y Venezuela. Como ejemplo de esta situación podemos mencionar el caso de Telefónica o Repsol que cuentan con varias subsidiarias en los países latinoamericanos, entre ellos, Brasil. Solo Bolivia, Costa Rica, Ecuador, El Salvador, Guatemala, Haití, Honduras y Jamaica permiten el uso de las NIC/NIIF. Los temas más controvertidos por parte de estos países en su proceso de incorporación de las normas internacionales son la corrección monetaria, la redefinición de las monedas funcionales y la consolidación. Con respecto a Brasil, empresas locales que ya han intentado un acercamiento han debido ajustar las siguientes partidas, a saber: bonus a los empleados, otros ingresos y gastos operativos, cargos diferidos, incentivos impositivos indirectos, reconocimiento de costes de pensión, etc.

Además, Alceu Haruo-Fuji (2008) comparó la normativa vigente del FASB, el IASB y la normativa brasileña, para la valoración y contabilización de títulos y valores mobiliarios, y concluyó que, en términos generales, hay armonía entre estas normativas sobre el particular, aunque con algunas diferencias. Destacó también la preocupación de Brasil por aumentar la armonía con las normas internacionales.

Otra investigación más específica de comparación entre las normas contables de Brasil 
y las normas internacionales del IASB fue la realizada por Luiz Nelson Guedes de Carvalho y Sirlei Lemes (2002), que plantearon la hipótesis de la existencia de un alto nivel de armonización entre ambos conjuntos normativos. A pesar de haberse encontrado con el inconveniente de la falta de legislación brasileña sobre algunos puntos que el IASB ya había desarrollado, lo que impidió una comparación más rigurosa, dedujeron que no había armonización entre ambos cuerpos normativos, dado que encontraron más de 20 categorías de hechos contables en los que la forma de ser reconocidos y/o medidos difiere sustantivamente.

Por otra parte, en lo relativo al estudio y análisis de proceso y las consecuencias del desarrollo de normas tendientes a la armonización, podemos sintetizar las investigaciones de Fabiano Maury Raupp e Ilse Maury Beuren (2005), que sostienen que el proceso de armonización puede verse facilitado por armonizaciones regionales (bloques económicos como el Mercosur, Nafta, UE o ALCA) para más tarde proceder a una armonización global, entendiendo que la armonización de las normas contables tiende a disminuir fronteras y contribuye al fortalecimiento de la integración entre países. Este trabajo recopila también opiniones de otros autores brasileños sobre el particular como:

- José Luís de Castro-Neto (1998), que define la armonización contable como el proceso de acercar las normas de contabilidad internacionales a las locales para que los estados financieros de diversos países se preparen a partir de un conjunto de principios comunes de medición.
- Marcelo Lima de Castro (2001), que sostiene que "la armonización de la terminología contable, de la medición contable y de los informes contables suministraría a los usuarios, estados financieros comparables y más apropiados para la toma de decisiones económicas". Insiste en que Brasil ve con buenos ojos la armonización mundial de la normativa contable, pero para que esto sea real se necesita que los países europeos y Estados Unidos dejen de gravar las exportaciones brasileñas.

En segundo lugar, Armando Madureira-Borely, José Antộnio Felgueiras da Souza, Walber Monteiro de Almeida y Júlio Sérgio de SouzaCardozo (2006) llevaron a cabo una investigación para comparar la normativa vigente en materia de combinaciones de negocios en UE (IASB), en Estados Unidos (FASB) y en Brasil. El artículo fue escrito y publicado antes de la reforma contable que tuvo lugar en Brasil (Ley 11638/2007) que introdujo alguna modificación al respecto. La conclusión fue que las legislaciones europeas y estadounidenses definían expresamente el concepto de combinaciones de negocios, al tiempo que dictaban normas sobre el particular. En Brasil, en cambio, no se define el término "combinaciones de negocios" en su legislación societaria de forma explícita. La Ley 6404/1976 la considera solo en la forma jurídica, es decir, absorción, fusión, escisión. En cuanto al registro contable, el IASB y el FASB utilizan el método de compra, y le dan a la combinación de negocios el carácter de un activo, de forma que cada organismo ha emitido una norma al respecto. Brasil, por su parte, 
no cuenta con normas legales sobre el tema. Las adquisiciones del control accionario serán registradas por el valor que se ha pagado por la adquisición de la inversión. La Ley 11638/2007 tampoco introdujo novedades al respecto.

En tercer término, Ana Cristina Faria y Mario Roberto Braga de Queiroz (2009), motivados por el proceso de armonización de las normas contables, indagaron sobre la demanda del mercado de trabajo en São Paulo para profesionales especializados en contabilidad internacional, y los requisitos de conocimientos técnicos, habilidades y competencias exigidas. Luego de recopilar ofertas de empleo que buscaban profesionales con conocimientos de contabilidad internacional, concluyeron que en esa ciudad, en 2007, se estaban buscando profesionales calificados en normativa estadounidense (US GAAP), principalmente. Un $84 \%$ de profesionales con conocimientos de las normas estadounidenses, frente a un $16 \%$ de conocimientos en normativa internacional. En 2008, sin embargo, la tendencia cambió ya que el mercado laboral empezó a demandar profesionales con conocimientos de las normas contables internacionales. El porcentaje de las ofertas de empleo que solicitaban conocimientos de las NIIF fue del 91\%. Esto se debió principalmente a que Brasil comenzó a mirar a la UE como fuente de recursos internacionales.

Así mismo, Mercedes Palacios-Manzano e Isabel Martínez-Conesa (2005) se plantearon el objetivo de observar el proceso de armonización contable en América Latina, para detallar los esfuerzos realizados hacia el logro de la convergencia de las normas contables. Estas autoras se han centrado en el estudio comparativo de los tratamientos contables dispares existentes entre las normas internacionales del IASB, los principios contables estadounidenses US GAAP y las normas argentinas, brasileñas, chilenas y mexicanas, para determinar las áreas en las que es preciso continuar avanzando para lograr esa convergencia. Entre las discrepancias más significativas sobresalen el tratamiento contable de la conversión de estados financieros expresados en moneda extranjera, los activos intangibles, los gastos de investigación y desarrollo, el inmovilizado material, la capitalización de los gastos financieros, las inversiones y las combinaciones de negocios. Los autores concluyeron que todavía es necesario seguir mejorando el proceso de búsqueda de un grupo de normas que permitan reducir la diversidad contable. Todo esto apoyado en la idea de que los estados financieros son preparados bajo una cultura que abarca aspectos legales, fiscales, sociales y culturales, al tiempo con diversos criterios de reconocimiento, valoración y publicación, que directamente influyen en la comprensibilidad y comparabilidad de la información financiera en el ámbito internacional.

Además, un estudio comparativo para examinar la forma de contabilización de títulos y valores mobiliarios fue el realizado por Haruo (2008). Su objeto de comparación fueron las normas del FASB (SFAS 115), las normas internacionales del IASB (concretamente la IAS 39) y la normativa brasileña Circular 3068/2001 del Banco Central de Brasil, BACEN. La conclusión que alcanzó este investigador fue que en su mayor parte, los tres cuerpos normativos eran semejantes, aunque con algunas diferencias puntuales. Así, a modo de ejem- 
plo, al considerar los títulos disponibles para la venta, obtuvo los siguientes resultados:

a. FASB (SFAS 115): establece que los beneficios o pérdidas no realizados de esta categoría serán considerados otros resultados.

b. IASB (IAS 39): determina para los beneficios o pérdidas no realizados de esta categoría que sean registrados como un componente separado del patrimonio líquido.

c. BACEN (Circular 3068/01): tratamiento similar a las normas del IASB.

Por otra parte, aunque las normas de auditoría no son objeto de este trabajo, cabe destacar la tarea investigadora de Elisabeth Yukie-Horita Ito, Jorge Katsumi-Niyama Paulo César de Melo-Mendes (2008), que intentaron evaluar el grado de adherencia de las normas brasileñas respecto del control de calidad de los servicios prestados por empresas dedicadas a la auditoría independiente para con instituciones financieras, aseguradoras y similares, respecto de las normas internacionales. La conclusión al respecto fue positiva.

Otro estudio comparativo fue el realizado por Zaina Said-El-Hajj y Lázaro Plácido-Lázaro (2001) en el que detectaron que habría mucho trabajo por delante de cara a conseguir la armonización contable en materia de combinaciones de negocios. De su trabajo comparativo entre los USGAAP, las NIC/NIIF y la normativa de su país (Brasil), detectaron importantes diferencias. A modo de ejemplo, merece la pena mencionar que las normas de Estados Unidos o las NIC/NIIF utilizan como parámetro de medición para las inversiones en participaciones de otras empresas, las acciones ordinarias con derecho a voto; mientras Brasil utiliza el capital social, que incluye las acciones preferentes. Mientras las normas de Estados Unidos y las NIC/NIIF pretenden reflejar la esencia económica de tales operaciones, Brasil basa su reconocimiento contable en la forma jurídica, con especial atención al impacto fiscal que esta pueda generar.

También Luiz Fernando Machado-Dinis (2009) comparó la normativa brasileña con las normas internacionales en lo referente a la elaboración del cash-flow o estado de flujo de efectivo. Con la aparición de la Ley 11638/2007, Brasil modificó su normativa en un intento de acercamiento a la normativa internacional. Por último, Kene Cristina Pereira (2003) comparó las prácticas contables internacionales de Estados Unidos y Brasil. Permitió establecer un paralelismo institucional ya que explica que el FASB (Estados Unidos) es el equivalente del $\mathrm{CFC}$ de Brasil. Ambos organismos, en sus respectivas áreas de influencia, emiten las normas de contabilidad. Del mismo modo, el American Institute of Certified Accountants, AICPA, se asemeja al IBRACON de Brasil ya que es el encargado de interpretar las normas contables.

\section{Conclusiones}

La armonización de las normas contables internacionales puede considerarse un objetivo prioritario para los agentes económicos interesados en la información financiera de empresas que buscan recursos y nuevos mercados fuera de sus fronteras. Los primeros pasos para la convergencia de las prácticas contables en el ámbito internacional ya se han dado, al fomentar la integración de los mercados y la presencia 
de capital extranjero en países de economías emergentes como Brasil.

Por su parte, las legislaciones contables de la mayoría de los países han experimentado también una tendencia armonizadora, que se incrementó a partir de 2005 cuando la UE abrió sus legislaciones locales hacia un cuerpo normativo único, con el IASB como su ente emisor. A esta iniciativa se fueron sumando otros países como Australia, China y Rusia, con lo que la internacionalización de la normativa contable experimentó un camino sin retorno. Incluso, Estados Unidos se adhirió parcialmente al proceso armonizador, lo cual marcó un hito, dada la tradicional resistencia mantenida hasta esos años.

De este modo, la contabilidad internacional se ha reformulado como respuesta al proceso de globalización que ha experimentado la economía mundial. Aspectos como las diferencias de cambio entre monedas en las que se realizan las operaciones, o la consolidación de los estados financieros, hacen cada vez más necesaria la homogeneización de la información contable.

Así mismo, en los últimos años, la presión ejercida por las empresas multinacionales ha impulsado la nueva formulación de la contabilidad internacional, siempre buscando la necesaria armonización. Los organismos reguladores contables y bursátiles han participado en el proceso legislativo que permitirá una plena armonización contable, al dirigir sus esfuerzos al logro de la convergencia mundial de las prácticas contables y la creación de un conjunto de normas contables de gran calidad que sea único y derive en mercados de capitales más competitivos y eficientes.
En efecto, organismos internacionales como el IASB, la FASB o la SEC han favorecido el proceso de convergencia de las prácticas contables como un instrumento de sinergia y compatibilidad entre mercados. De todas las organizaciones implicadas en este objetivo, el IASB ha irrumpido como la más ambiciosa. Muchos países han decidido adherirse a este organismo, al conciliar sus normas contables con las emitidas por este, lo que confirma los resultados de determinadas investigaciones, como la de Mercedes Palacios-Manzano e Isabel Martínez-Conesa (2005).

En Brasil, esta necesidad de armonización contable afecta a la competitividad de sus organizaciones. Ha sido prioritario para el gobierno el perfeccionamiento de los mercados de capitales, con base en la idea de que mercados dinámicos y profundos conforman una gran alternativa de cara a la financiación externa. El objetivo principal es crear las condiciones necesarias para la asignación efectiva del ahorro de empresas y particulares hacia la inversión productiva y la disminución de sus costes de capital. Brasil es hoy uno de los países con mayor potencial económico del mundo, dada su estructura poblacional, el ritmo de su crecimiento económico y la presencia de importantes recursos como el petróleo. Por su volumen de comercio internacional, está entre los primeros veinticinco países del mundo, siendo creciente el comercio y las transacciones financieras con países del entorno europeo.

España, por su parte, ha incrementado su participación en ese país desde la década de los noventa, con grandes inversiones y mayor presencia del empresariado español. Telefónica, 
Santander o Sacyr, por nombrar algunas, han desarrollado importantes líneas de inversiones y negocios en territorio brasileño. Dado que España y sus empresas más relevantes tienen intereses en este país sudamericano y las empresas brasileñas amplían su radio de acción hacia países europeos, resulta oportuno investigar el grado de armonización contable de ambas normativas, así como su grado de acercamiento respecto de las Normas Internacionales de Información Financiera. En este trabajo, previo a tal comparativa, se destaca el esfuerzo armonizador que los organismos y las normas de ambos países han desarrollado en los últimos años, en particular desde 2005.

Una vez que se estudien sus similitudes y diferencias, y se pueda determinar el grado de acercamiento alcanzado, podrá utilizarse este caso como referencia para analizar el grado de armonización contable internacional y se podrían realizar, posteriormente, otros análisis comparativos similares entre legislaciones contables de otros países. Analizada la literatura especializada durante el período 2000-2011, no hay ningún trabajo comparativo específico entre las normativas contables de España y Brasil. En el período observado solo aparecen estudios comparativos entre otros cuerpos normativos como España y las NIC/NIIF, Brasil y los US GAAP, o Brasil y las NIC/NIIF.

Tal como se ha evidenciado en el presente trabajo, ambas legislaciones han implementado en los últimos años importantes reformas contables. En España, con su nuevo PGC 2007 y la incorporación del PGC Pyme y en Brasil, con las leyes 11638/2007 y 11941/2009. Los dos países han promovido una aproximación a la normativa internacional, que consecuentemente ha llevado a un acercamiento entre sus respectivas normativas contables. Con todo, podría concluirse, a priori, que la armonización contable entre España y Brasil es ya un hecho, pero debe mantenerse el ritmo de reformas legislativas para conseguir un mayor grado de convergencia.

\section{Referencias}

\section{Autores}

Arcas-Pellicer, María José; Moneva-Abadía, José Mariano \& Torres-Pradas, Lourdes (2003). Contabilidad financiera avanzada: normativa española e internacional. Madrid: Paraninfo.

Beuren, Ilse Maria; Santos-Cardoso, Rodrigo dos; Facin-Lavarda, Carlos Eduardo \& Ripoll-Feliu, Vicente M. (2009). Gestão de matérias-primas em indústrias de conserva de pescado do Brasil e da Espanha. Revista Iberoamericana de Contabilidad de Gestión, 7 (13), 3-25. Disponible en: http:// www.observatorio-iberoamericano.org/ RICG/N\%C2\%BA_13/I.M._Beuren,_R.S._ Cardoso,_\%20C.E._Lavarda,_V._Ripoll.pdf Caïs, Jordi (1997). Metodología del análisis comparativo. Colección Cuadernos Metodológicos, 21. Madrid: Centro de Investigaciones Sociológicas.

Carvalho, Luiz Nelson-Guedes de \& Lemes, Sirlei (2002). Padrões contábeis internacionais do IASB: um estudo comparativo como as normas contábeis brasileiras e sua aplicação. UnB Contábil, 6 (2), 61-89. Disponible en: http://www. 
cgg-amg.unb.br/index.php/contabil/article/ view/208

Castro, Marcelo Lima de (2001). Uma contribuição ao estudio de harmonização das normas contábeis na era da globalização. São Paulo. $1^{\circ}$ Seminário USP de Contabilidade, 01 e 02 de outubro de 2001. São Paulo: Universidade de São Paulo, USP. Disponible en: http://www.fucape.br/_public/ producao_cientifica/2/Castro\%20-\%20 Uma\%20contribui\%C3\%A7\%C3\%A3o\%20 ao\%20estudo\%20da\%20 harmoniza\%C3\%A7\%C3\%A3o.pdf Castro-Neto, José Luís (1998). Contribuição ao estudo de prática harmonizada da contabilidades na União Européia.

Tese (Doutorado em Contabilidade e controladoria, Faculdade de Economía, Administração e Contabilidade, Universidade de São Paulo, USP, São Paulo.

Cea-García, José Luis (2001). Armonización contable internacional y la reforma de la contabilidad en España. Madrid: Ministerio de Economía y Competitividad, Instituto de Contabilidad y Auditoría de Cuentas, ICAC.

Choi, Frederick D. S. \& Meek, Gary K. (2011). International Accounting. New Jersey: Pearson New International.

Cuéllar-Fernández, Beatriz; Demartini, Paola; Moneva-Abadía, José Mariano \& Paolini, Mauro (2001). El impacto de la información financiera para la pyme en la Unión Europea: el caso de Italia y España. Técnica Contable, 53 (626), 131-144. Disponible en: http://www. tecnicacontable.com/ver_detalleArt. asp? idArt $=10782 \&$ action $=$ ver
Faria, Ana Cristina \& Braga de Queiroz, Mario Roberto (2009). Demanda de profissionais habilitados em contabilidade internacional no mercado de trabalho da cidade de São Paulo. Revista Universo Contábil, 5 (1), 55 71. Disponible en: http://www.redalyc.org/ pdf/1170/117015043005.pdf

García-Fonti, Inés (2008). Predominio de las NIIF en Latinoamérica. Revista de la Asociación Española de Contabilidady Administración de Empresas, AECA, 84, 2829. Disponible en: http://www.aecal.org/ revistaeca/revista84/84.pdf

Giner-Fillol, Arturo; Labatut-Serer, Gregorio \& Ripoll-Feliu, Vicente (2009). Adaptación del Plan General de Contabilidad Español a las Normas Internacionales de Contabilidad y a las Normas Internacionales de Información Financiera. La experiencia de la autoridad portuaria de Valencia. Revista de Contabilidade do Mestrado em Ciências Contábeis da Universidade do Estado do Rio de Janeiro, UERJ, 14 (1), 1-18. Disponible en: http://www.spell.org.br/documentos/ download/17

Giner-Inchausti, Begoña (2003). El nuevo proceso de regulación contable en Europa: cambios en el proceso y en las normas. Revista de la Asociación Española de Contabilidad y Administración de Empresas, AECA, 65, 13-17.

Giner-Inchausti, Begoña (2008). Recientes desarrollos en relación con la adopción de las NIIF en la UE (y en los EEUU). Revista de la Asociación Española de Contabilidad y Administración de Empresas, 83, 42-44. 
Giner-Inchausti, Begoña \& Mora-Enguídanos, Araceli (2001). El proceso de armonización contable en Europa: análisis de la relación entre la investigación contable y la evolución de la realidad económica. Revista Española de Finanzas y Contabilidad, REFC, 30 (107), 103-128. Disponible en: http://www.aeca.es/pub/refc/articulos. php?id $=0165$

Haruo-Fuji, Alceu (2008). Contabilização de títulos e valores mobiliários: uma comparação entre as normas brasileiras, do FASB e do IASB. Revista Contabilidade e Finanças, São Paulo, 19 (47), 112-123. Disponible en: http:// www.scielo.br/scielo.php?pid=S1519$70772008000200010 \&$ script $=$ sci_arttext

Katsumi-Niyama, Jorge (2010). Contabilidade internacional. São Paulo: Editora Atlas.

Kvaal, Erlend \& Nobes, Christopher (2010). International Differences in IFRS Policy Choice: A Research Note. Accounting and Business Research, 40 (2), 173-187.

Laínez-Gadea, José Antonio (2001). Manual de contabilidad internacional. Madrid: Pirámide.

López-Combarros, José Luis (2002a).

Armonización contable internacional: perspectivas del proceso de implantación de las Normas Internacionales de Contabilidad. Revista de la Asociación Española de Contabilidad y Administración de Empresas, 60, ejemplar dedicado al $\mathrm{X}$ Encuentro AECA: Nuevas tendencias en contabilidad y administración de empresas y del sector público: la empresa ibérica ante la globalización, 7-8.
López-Combarros, José Luis (2002b). Reforma contable: su necesidad. Partida Doble, 136, 52-59.

Lorca-Fernández, Pedro (2001). El Nuevo IASC. Partida Doble, 120, 12-23.

Machado-Dinis, Luiz Fernando (2009). Demonstrações dos fluxos de caixa nas normas brasileira, internacional e norteamericana. Pensar Contábil, Río de Janeiro, 11 (45), 41-49. Disponible en: http://webserver. crcrj.org.br/asscom/Pensarcontabil/ revistaspdf/revista\%2045.pdf

Madureira-Borely, Armando; Felgueiras da Souza, José Antộnio; Monteiro de Almeida, Walber \& Souza-Cardozo, Júlio Sérgio de (2006). Business combination: análise comparativa das normas européias, norte-americanas e brasileiras. Pensar Contábil, Río de Janeiro, 7 (30), 35-41. Disponible en: http://webserver.crcrj.org. br/asscom/Pensarcontabil/revistaspdf/ revista\%2030.pdf

Nobes, Christopher (1984). International Classification on Financial Reporting. Croom Helm series on International Accounting and Finance. London: St. Martin's Press. Nobes, Christopher (1998). Towards a General Model of the Reasons for International Differences in Financial Reporting. Abacus, 34 (2), 162-187.

Nobes, Christopher (2008). Accounting Classification in the IFRS Era. Australian Accounting Review, 18 (3), 191-198.

Nobes, Christopher \& Parker, Robert (1998). Comparative International Accounting. Salisbury, United Kingdom: Prentice Hall Europe. 
Nobes, Christopher \& Parker, Robert (2010). Comparative International Accounting. Essex, United Kingdom: Prentice Hall Europe.

Olleros-Rodríguez, Antonio M. (2008). Estado de implementación de las NIIF en la Unión Europea. Técnica Contable, 708, 12-15.

Disponible en: http://www.tecnicacontable. com/ver_seccion.asp?idSeje $=14702$

Padoveze, Clóvis Luis (2009). Manual de contabilidade básica. São Paulo: Editora Atlas.

Palacios-Manzano, Mercedes \& MartínezConesa, Isabel (2005). El proceso de armonización contable en Latinoamérica: camino hacia las normas internacionales. Revista de Contabilidade e Finanças, USP, São Paulo, 16 (39), 103-117. Disponible en: http://www.redalyc.org/ pdf/2571/257119534009.pdf

Pereira, Kene Cristina (2003). Uma iniciação a comparação das práticas contábeis internacionais (IAS), americanas (EUA) e brasileiras (BR). Pensar Contábil, Río de Janeiro, 6 (21), 19-24. Disponible en: http://webserver.crcrj.org.br/asscom/ Pensarcontabil/revistaspdf/revista\%2021.pdf Pulido-Álvarez, Antonio (2001). Armonización contable internacional: algunas reflexiones. Partida Doble, 120, 6-11

Raupp, Fabiano Maury \& Beuren, Ilse Maria (2005). A supremacía contábil dos Estados Unidos como aspecto dificultador à harmonizaçao das normas contábeis no ámbito da ALCA. Pensar Contábil, Río de Janeiro, 7 (29), 23-29. Disponible en: http://webserver.crcrj.org.br/asscom/ Pensarcontabil/revistaspdf/revista\%2029.pdf
Rejón-López, Manuel (2005). La estación de penitencia de los grupos cotizados españoles: análisis de las NIC en la prensa española. Revista de la Asociación Española de Contabilidad y Administración de Empresas, AECA, 71, 20-23. Disponible en: http://www.aeca1.org/revistaeca/ revista71/71.pdf

Sabi-Marcano, Xavier; Saladrigues-Sole, Ramón; Vendrell-Vilanova, Anna \& TenaTarruella, Anna (2001). La comparación de las cuentas anuales de las empresas europeas. ¿Son las centrales de balances un instrumento válido? Técnica Contable, 630, 441-458. Disponible en: http://www. tecnicacontable.com/ver_detalleArt. asp?idArt $=10681 \&$ action $=$ ver

Said-El-Hajj, Zaina \& Plácido-Lisboa, Lázaro (2001). Business Combinations e consolidação das demonstrações contábeis: uma abordagem comparativa entre os pronunciamentos e normas dos USGAAP, IASC e Brasil. Revista Contabilidade \& Finanças, 16 (27), 33-58. Disponible en: http://www.eac.fea.usp.br/cadernos/ completos/cad27/Revista_27_parte_3.pdf

Souza-Barros, Luana Paula de; CheinSchekaiban, Nazhle F.; Simeone-Gomes, Josir \& Ripoll-Feliu, Vicente (2008). Estudo comparativo na área de contabilidade gerencial entre Brasil, México e Espanha. Revista Iberoamericana de Contabilidad de Gestión, España, 12, 1-17. Disponible en: http://www.observatorio-iberoamericano. org/RICG/N\%C2\%BA_12/Souza-CheinGomes_y_Ripoll.pdf 
Yukie-Horita Ito, Elisabeth; Katsumi-Niyama, Jorge \& Melo-Mendes, Paulo César de (2008). Controle de qualidade dos serviços de auditoria independente: um estudo comparativo entre as normas brasileiras e as normas internacionais. Revista UnB Contábil, 11 (1-2), 312-328. Disponible en: http://www.spell.org.br/documentos/ download/8449

\section{Legislación}

Brasil. Banco Central de Brasil, BACEN. Circular 3068/2001, de 8 de novembro de 2001, estabelece critérios para registro e avaliação contábil de títulos e valores mobiliários. Disponible en: http://www.cnb. org.br/CNBV/circulares/cir3068-2001.htm

Brasil. Conselho Federal de Contabilidade, CFC. Resolução 750/1993, dispõe sobre os princípios de contabilidade (PC). Diário Oficial da União, 31 de dezembro de 1993. Disponible en: http://www.portaldecontabilidade.com.br/ legislacao/resolucaocfc774.htm

Brasil. Conselho Federal de Contabilidade, CFC. Resolução 1374/2011, dispõe sobre Estrutura Conceitual para Elaboração e Divulgação de Relatório Contábil-Financeiro. Diário Oficial da União, 16 de dezembro de 2011. Disponible en: http://www. normaslegais.com.br/legislacao/resolucaocfc-1374-2011.htm

Brasil. Ley 6404/1976. Disponible en: http:// www.planalto.gov.br/ccivil_03/leis/ 16404consol.htm

Brasil. Ley 11638/2007, que modifica la Ley 6404/1976. Disponible en: http://www. planalto.gov.br/ccivil_03/_ato20072010/2007/lei/l11638.htm

Brasil. Ley 11941/2009, que modifica las leyes 6404/1976 y 11638/2007. Disponible en: http://www.planalto.gov.br/ccivil_03/_ ato2007-2010/2009/lei/l11941.htm

España. Código de Comercio, 16 de octubre de 1885. Boletín Oficial del Estado, BOE, 289, 16 de octubre de 1885. Disponible en: https:// www.boe.es/datos/pdfs/BOE/1885/289/ R00169-00613.pdf. Modificado por la Ley 19/1989. Boletín Oficial del Estado, BOE, 178, 27 de julio de 1989. Disponible en: https:// www.boe.es/boe/dias/1989/07/27/pdfs/ A24085-24110.pdf. Ley 24/2001. Boletín Oficial del Estado, BOE, 313, 31 de diciembre de 2001. Disponible en: http://www.boe. es/boe/dias/2001/12/31/pdfs/A5049350619.pdf. Ley 34/2002. Boletín Oficial del Estado, BOE, 166, 12 de julio de 2002. Disponible en: http://www.boe.es/boe/ dias/2002/07/12/pdfs/A25388-25403.pdf. Ley 22/2003. Boletín Oficial del Estado, BOE, 164, 10 de julio de 2003. Disponible en: http://www.boe.es/boe/dias/2003/07/10/ pdfs/A26905-26965.pdf. Ley 62/2003. Boletín Oficial del Estado, BOE, 313, 31 de diciembre de 2003. Disponible en: http:// www.boe.es/boe/dias/2003/12/31/pdfs/ A46874-46992.pdf. Ley 2/2007. Boletín Oficial del Estado, BOE, 65, 16 de marzo de 2007. Disponible en: http://www.boe.es/ boe/dias/2007/03/16/pdfs/A11246-11251. pdf. Ley 16/2007. Boletín Oficial del Estado, BOE, 160, 5 de julio de 2007. Disponible en: http://www.boe.es/boe/dias/2007/07/05/ pdfs/A29016-29047.pdf 
España. Decreto 530/1973, por el que se aprueba el Plan General de Contabilidad. Boletín Oficial del Estado, BOE, 79, 2 de abril de 1973. Disponible en: https://www.boe.es/ diario_boe/txt.php?id=BOE-A-1973-478

España. Ley 19/1988, de Auditoría de Cuentas. Boletín Oficial del Estado, BOE, 169, 15 de julio de 1988. Disponible en: https://www. boe.es/boe/dias/1988/07/15/pdfs/A2187421879.pdf

España. Ley 2/1995, Ley de Sociedades de Responsabilidad Limitada. Boletín Oficial del Estado, BOE, 71, 24 de marzo de 1995. Disponible en: https://www.boe.es/diario_ boe/txt.php?id=BOE-A-1995-7240

España. Real Decreto 1643/1990, por el cual se aprueba el Plan General de Contabilidad. Boletín Oficial del Estado, BOE, 310, 27 de diciembre de 1990. Disponible en: https://www.boe.es/diario_boe/txt. php?id=BOE-A-1990-31126

España. Real Decreto 1815/1991, por el cual se aprueban las normas para formulación de las cuentas anuales consolidadas. Boletín Oficial del Estado, BOE, 310, 27 de diciembre de 1991. Disponible en: https://www.boe.es/ diario_boe/txt.php?id=BOE-A-1991-30762

España. Real Decreto 1784/1996, por el cual se aprueba el Reglamento del Registro Mercantil. Boletín Oficial del Estado, BOE, 184, 31 de julio de 1996. Disponible en: https://www. boe.es/boe/dias/1996/07/31/pdfs/A2357423636.pdf

España. Real Decreto 1514/2007, Plan General de Contabilidad. Boletín Oficial del Estado, BOE, 278, 20 de noviembre de 2007. Disponible en: http://www.boe.es/diario_boe/txt. php?id=BOE-A-2007-19884

España. Real Decreto 1515/2007, Plan General de Contabilidad de Pequeñas y Medianas Empresas y los criterios contables específicos para microempresas. Boletín Oficial del Estado, BOE, 279, 21 de noviembre de 2007. Disponible en: http://www.boe.es/buscar/ doc.php?id=BOE-A-2007-19966

España. Real Decreto Legislativo 1564/1989, texto refundido de la Ley de Sociedades Anónimas, modificada por Ley 16/2007. Boletín Oficial del Estado, BOE, 310, 27 de diciembre de 1989. Disponible en: https://www.boe.es/buscar/doc. php?id=BOE-A-1989-30361

España. Real Decreto Legislativo 1/2010, texto refundido de la Ley de sociedades de capital. Boletín Oficial del Estado, BOE, 161, 3 de julio de 2010. Disponible en: http://www.boe.es/ diario_boe/txt.php?id=BOE-A-2010-10544

Parlamento Europeo. Reglamento 1606/2002/

$C E$, relativo a la aplicación de normas internacionales de contabilidad.

Disponible en: http://europa.eu/ legislation_summaries/internal_market/ single_market_services/financial_services_ general_framework/126040_es.htm

Unión Europea. Cuarta Directiva 78/660/CEE, relativa a las cuentas anuales de determinadas formas de sociedad. Diario Oficial, L 222, 14 de agosto de 1978. Disponible en: http:// europa.eu/legislation_summaries/internal_ market/businesses/company_law/126009_ es.htm

Unión Europea. Séptima Directiva 83/349/ CEE, relativa a las cuentas consolidadas. 


\section{ARMONIZACIÓN CONTABLE EN ESPAÑA Y BRASIL / F. GRACIA, C. SAN JUAN, A. RODRÍGUEZ / 425}

Diario Oficial, L 193, 18 de julio de 1983.

Disponible en: http://europa.eu/legislation_ summaries/internal_market/businesses/ company_law/126010_es.htm

- Fecha de recepción: 14 de marzo de 2013

- Fecha de aceptación: 28 de febrero de 2013

- Disponible en línea: 01 de julio de 2014

\section{Para citar este artículo}

Gracia-Sarubbi, Fernando; San Juan-Pajares, César Antonio \& Rodríguez-López, Ángel (2014). Evolución del proceso de armonización contable en España y Brasil en el período 1973-2013. Cuadernos de Contabilidad, 15 (38), 397-425.

doi: 10.11144/Javeriana.cc15-38.epac 
